\title{
Pharmacokinetics of Intravenous Cocaine Across the Menstrual Cycle in Rhesus Monkeys
}

\author{
Suzette M Evans ${ }^{*, 1,2}$ and Richard W Foltin ${ }^{1,2}$ \\ 'Division on Substance Abuse, New York State Psychiatric Institute, New York, NY, USA; ${ }^{2}$ Department of Psychiatry, College of Physicians and \\ Surgeons of Columbia University, New York, NY, USA
}

\begin{abstract}
Several studies in rodents suggest that there are sex differences in response to cocaine that are related to fluctuations in the ovarian hormones of females. Female rhesus monkeys have menstrual cycles that are remarkably similar to human menstrual cycles in both duration and hormonal variations. Therefore, data obtained in monkeys should be an ideal model for assessing the effects of cocaine across the menstrual cycle in humans. The present study assessed the acute effects of intravenous cocaine $(0,0.25,0.50$, and $1.00 \mathrm{mg} / \mathrm{kg})$ in five female rhesus monkeys during four phases of the menstrual cycle: menses, midfollicular, periovulatory, and midluteal. To reduce the effects of stress that can occur from sedation, all animals were trained to enter primate chairs so that repeated blood samples could be obtained in awake animals. Hormone levels for estradiol and progesterone were measured each session before cocaine administration. Cocaine and cocaine metabolite plasma levels were measured at 5, 15, 30, 45, 60, and 90 min after cocaine administration. Similarly, levels of luteinizing hormone $(\mathrm{LH})$ were measured before, 15, 30, 45, 60, and 90 min after cocaine administration. Within 5 min of cocaine administration, cocaine plasma levels peaked and dose-dependent behavioral changes (ie increased motor activity, mydriasis, and refusal of treats) were observed. These effects typically resolved in I5-30 min. There were few differences in the pharmacokinetic profile of cocaine across the menstrual cycle. However, the cocaine metabolites, BZE and EME, did vary across the menstrual cycle, with both being increased in the luteal phase, particularly following the highest dose of cocaine. In addition, unlike previous studies, cocaine did not produce consistent increases in LH levels. Rather, the change in LH levels depended on menstrual cycle phase and cocaine dose. In summary, there is little evidence that the pharmacokinetics of cocaine vary as a function of menstrual cycle phase.

Neuropsychopharmacology (2004) 29, 1889-1900, advance online publication, 12 May 2004; doi: I 0. I038/sj.npp. 1300486
\end{abstract}

Keywords: cocaine; pharmacokinetics; cocaine metabolites; rhesus monkey; menstrual cycle; luteinizing hormone

\section{INTRODUCTION}

Numerous preclinical studies have documented that female rodents are more sensitive than male rodents to several behavioral effects of stimulant administration (eg Roberts et al, 1989; Sell et al, 2000), and these differences appear to be related to fluctuations in the ovarian hormone levels of females (eg Roberts et al, 1987; Grimm and See, 1997; Quiñones-Jenab et al, 1999; also see review by Lynch et al, 2002). For example, during estrus, female rats (1) have higher progressive ratio breakpoints for cocaine selfadministration (Roberts et al, 1989; Hecht et al, 1999); (2) show greater disruptions in the regulation of cocaine selfadministration (Lynch et al, 2000); and (3) select the highest

\footnotetext{
*Correspondence: SM Evans, Division on Substance Abuse, New York State Psychiatric Institute, I05I Riverside Drive, Unit 66, New York, NY 10032, USA, Tel: + I 212543 5895, Fax: + I 2125436018. E-mail: sel8@columbia.edu

Received 2 September 2003; revised 9 February 2004; accepted 14 April 2004

Online publication: 16 April 2004 at http://www.acnp.org/citations/ Npp04 I 60403399/default.pdf
}

cocaine dose (Lynch et al, 2000). Sex differences in humans following cocaine administration have generally been more subtle (eg Kosten et al, 1996; Lukas et al, 1996; Evans et al, 1999; Sofuoglu et al, 1999). However, in one study in humans (Haney et al, 1998), females had a higher progressive ratio breakpoint for the highest dose of i.v. cocaine than males. Further, several studies have shown that ratings such as 'High' are increased more during the follicular phase than the luteal phase in women after stimulant administration (Justice and de Wit, 1999; Sofuoglu et al, 1999; Evans et al, 2002). Taken together, these data indicate that there are sex differences in the behavioral response to stimulants, and that these differences are related to ovarian hormone levels.

Given the increasing evidence that there are sex differences in response to cocaine, and that these differences might be related to changes in ovarian hormone levels, it is crucial to determine if these differences are related to (1) pharmacokinetic differences across the menstrual cycle and/or (2) pharmacokinetic differences between males and females. Although several studies have attempted to address this question in humans, the results 
have been inconsistent. For instance, no differences in cocaine plasma levels were observed between men and women following a single dose of intranasal cocaine (Kosten et $a l, 1996)$. In another study (Evans et al, 1999), women had higher cocaine plasma levels than men after smoking six doses of $50 \mathrm{mg}$ cocaine, but this was most likely due to the fact that women weighed less than men and dosing was not adjusted based on body weight. While Lukas et al (1996) found that men had higher cocaine plasma levels than women and women had higher cocaine plasma levels during the follicular phase compared to the luteal phase following a single dose of $0.9 \mathrm{mg} / \mathrm{kg}$ intranasal cocaine, other studies have not supported these findings. For instance, Sofuoglu et al (1999) showed no sex or menstrual cycle phase differences in cocaine plasma levels following a single dose $(0.4 \mathrm{mg} / \mathrm{kg})$ of smoked cocaine. Similarly, following a range of repeated doses of smoked cocaine (Evans et al, 2002) in women, there were no differences in cocaine plasma levels between the follicular and the midluteal phases of the menstrual cycle. Lastly, the only pharmacokinetic difference found following a single dose of either 0.2 or $0.4 \mathrm{mg} / \mathrm{kg}$ i.v. cocaine was that cocaine plasma levels after $0.4 \mathrm{mg} / \mathrm{kg}$ cocaine peaked faster in follicular phase women compared to luteal phase women and men (Mendelson et al, 1999b). Taken together, the limited data in humans suggest that there are minimal differences in cocaine pharmacokinetics between men and women, or between the follicular and luteal phases of the menstrual cycle in women. Unfortunately, there are several limitations with the cocaine pharmacokinetic data collected in these studies, including differences in the route of administration, the limited number of doses tested, and not all studies tested the same women across the menstrual cycle. Also, with the exception of one study (Mendelson et al, 1999b), a full time course was not captured to assess the pharmacokinetic profile of cocaine.

Clearly, collecting cocaine pharmacokinetic data across a range of doses at precise phases of the menstrual cycle in humans is quite time consuming and difficult. In contrast to the rodent estrous cycle, the female rhesus monkey is an ideal model for assessing the effects of cocaine across the menstrual cycle because they have a menstrual cycle almost identical in length and hormonal fluctuation to that of humans. Three studies assessed the pharmacokinetic and behavioral effects of i.v. cocaine in male and female rhesus monkeys (Misra et al, 1977; Saady et al, 1994, 1995), but they did not directly compare males and females and did not control for menstrual cycle phase. Mello, Mendelson and co-workers have conducted a series of elegant studies investigating the effects of cocaine on gonadal and pituitary hormones in rhesus monkeys. For instance, they have demonstrated that acute doses of i.v. cocaine (0.4 and $0.8 \mathrm{mg} / \mathrm{kg}$ ) increase LH plasma levels and decrease prolactin levels in female monkeys during the early follicular phase (Mello et al, 1990a). While no differences in cocaine plasma levels were reported between males and females (Mello et al, 1993), cocaine plasma levels were only measured at a single time point (10 min after the injection) and direct comparisons were not made between follicular (Mello et al, 1990b) and luteal phase females (Mello et al, 1993). The only pharmacokinetic difference between males and midfollicular females following $0.8 \mathrm{mg} / \mathrm{kg}$ i.v. cocaine was that females had lower cocaine plasma levels $10 \mathrm{~min}$ after the injection, although there were no differences in peak cocaine plasma levels, time to peak, or half-life (Mendelson et al, 1999a). In a subsequent study (Mello et al, 2000), midfollicular phase females were directly compared to midluteal phase females following a single i.v. dose $(0.8 \mathrm{mg} / \mathrm{kg})$ of cocaine and no differences in peak cocaine plasma levels or time to peak were observed. Lastly, a recent study compared the effects of repeated doses of i.v. cocaine $(0.4$ and $0.8 \mathrm{mg} / \mathrm{kg})$ in male and female monkeys (Mello et al, 2002) and again found no differences in peak cocaine plasma levels between males and females, although the time to peak was slightly longer for females than males. In that study, normally cycling females were tested in the midfollicular phase, but not all of the females tested were normally cycling.

Based on the limited data available in both monkeys and humans, there appear to be minimal differences in the pharmacokinetics of cocaine across the menstrual cycle. However, the studies that have been conducted in monkeys have some of the same limitations as the human studies, making it difficult to definitively conclude that there are no differences in cocaine plasma levels across the menstrual cycle. Thus, the present study was designed to extend previous research conducted in female monkeys by testing a range of i.v. cocaine doses at four distinct phases of the menstrual cycle using a within-subject design. Further, in the present study, cocaine metabolite levels, specifically benzoylecgonine (BZE) and ecgonine methyl ester (EME), were also measured. Lastly, since most previous studies have reported that cocaine administration increases $\mathrm{LH}$ plasma levels in human and non-human primates (see review by Mello and Mendelson, 2002), LH levels were measured before and after cocaine administration.

\section{METHODS}

\section{Animals}

Five adult experimentally naive female rhesus monkeys (Macaca mulatta), weighing between 5.8 and $9.4 \mathrm{~kg}$, lived under the housing conditions described below for the 8month duration of this experiment. Each monkey received a daily chow ration designed to maintain a stable body weight (4-10 High protein monkey diet \#5047 chow, $15 \mathrm{~g} / \mathrm{chow}$, $3.37 \mathrm{kcal} / \mathrm{g}$; LabDiets ${ }^{\circledR}$, PMI Feeds, Inc, St Louis, MO), chewable vitamins, and a piece of fruit daily. Body weights, determined weekly, remained stable throughout the study. Each monkey had access to two identically sized chambers $(61.5 \mathrm{~cm}$ wide $\times 66.5 \mathrm{~cm}$ deep $\times 88 \mathrm{~cm}$ high; Hazleton Systems, Inc., Aberdeen, MD) connected by $40 \mathrm{~cm} \times 40 \mathrm{~cm}$ openings. The sides of the chambers are slotted for a solid panel that prevents movement from one chamber to the next. These partitions were inserted when it was necessary to confine a monkey to one chamber (eg cage cleaning, TB testing). Water was freely available from spouts located on the back wall of both chambers. The room lights were illuminated from 0700 to 1900 . The menstrual cycle of each monkey was monitored daily by recording the onset and duration of menstrual bleeding. All aspects of animal maintenance and experimental procedures complied with the US National Institutes of Health Guide for Care and Use of Laboratory Animals, and were approved by the New York 
State Psychiatric Institute Animal Care and Use Committee. The health of the monkeys was routinely monitored by the investigators and a veterinarian.

As acute placement of female rhesus monkeys in primate chairs during the follicular phase increases cortisol and adrenocorticotropin hormone $(\mathrm{ACTH})$ release and decreases pulsatile LH release (Norman et al, 1994), female monkeys were acclimated to daily chair restraint and received their daily fruit and vitamin ration while in a chair at the same time each day. Using two technicians, a pole and collar system was used to guide the monkeys out of the chamber and into the chair. Once monkeys were seated in the chair, their feet were placed into open-toed shoes mounted on the foot bars in order to secure the feet and legs for repeated blood sampling. All monkeys were acclimated to this procedure 4-5 days each week for 1-2 menstrual cycles before the study started. To reduce associating chair restraint with experimental sessions, throughout the study monkeys were chair restrained two additional days each week when they received treats, but did not have blood drawn.

\section{Cocaine Administration and Sample Collection}

The acute pharmacokinetic effects of various doses of cocaine were tested across the four phases of the menstrual cycle. Each session lasted approximately $2 \mathrm{~h}$ and began at 0930. A 21-gauge butterfly cannula (Vacutainer ${ }^{\circledR}$ Brand blood collection set; Becton Dickinson, Franklin Lakes, NJ) was inserted into a saphenous vein in one leg and secured with tape for repeated blood collection. After obtaining a baseline blood sample for EST, PROG, and LH plasma levels through a butterfly cannula in one leg, monkeys received a single dose of cocaine $(0,0.25,0.50$, or $1.00 \mathrm{mg} / \mathrm{kg})$ administered in a $0.5 \mathrm{ml}$ volume over $10 \mathrm{~s}$ through a butterfly cannula in the alternate leg (plasma for determination of cocaine levels cannot be taken from the same vein used to administer cocaine), followed by a $1.0 \mathrm{ml}$ saline flush. Cocaine and metabolite levels were determined 5, 15, $30,45,60$, and $90 \mathrm{~min}$ after the cocaine injection. LH levels were determined before and 15, 30, 45, 60, and 90 min after the cocaine injection. Between each blood sample, saline was periodically flushed into the i.v. line to maintain patency and immediately before each sample, $0.5 \mathrm{ml}$ of blood was withdrawn from the i.v. line and discarded. Over the course of an entire session, a total of $16 \mathrm{ml}$ of blood was drawn. Because of the number of doses tested in the present study and the number of menstrual cycle phases tested, we did not collect samples beyond $90 \mathrm{~min}$ and did not also assay other hormones such as cortisol and prolactin.

Each female monkey was tested at two to three cycle phases each month to obtain a complete dose-response function at each cycle phase, that is, three cocaine doses and placebo were tested at each of four cycle phases for a total of 16 test sessions per female monkey. The menstrual and follicular phases of the menstrual cycle were defined based on the onset of menstrual bleeding, with menstrual sessions on days 1-5 and follicular sessions on days 6-10 after the onset of menses. For the periovulatory and luteal sessions, sessions were scheduled based on the typical length of each individual monkey's menstrual cycle. Periovulatory sessions were scheduled approximately on days 12-15 after the onset of menses, whereas luteal sessions were scheduled approximately on days 19-23 after the onset of menses. These days were later in monkeys who had menstrual cycles $>28$ days. While ovulation occurs shortly after a surge in LH and this is the primary indicator of when ovulation has occurred, determining LH levels on a daily basis was not possible. Moreover, LH levels in monkeys could only be assayed by the laboratory in batches every 3 months, thus it was not possible to use the LH surge as a more precise method to schedule periovulatory and luteal sessions. However, baseline estradiol and progesterone levels were used to define menstrual cycle phase and a menstrual cycle was determined as ovulatory if progesterone levels were $\geqslant 1.5 \mathrm{ng} / \mathrm{ml}$ during the periovulatory or luteal phases. In the event that sessions were aborted due to problematic data (eg difficulty in maintaining venous access, problematic cocaine plasma levels, anovulatory menstrual cycle), these sessions were excluded from the data analyses and repeated during another menstrual cycle.

\section{Cocaine}

Cocaine hydrochloride (provided by The National Institute on Drug Abuse) was dissolved into sterile saline for injection U.S.P., in a concentration of 5,10 , or $20 \mathrm{mg} / \mathrm{ml}$, to allow similar injection volumes across the doses tested. Injections were administered into one of the saphenous veins of the leg in a $0.5 \mathrm{ml}$ volume over $10 \mathrm{~s}$, followed by $1.0 \mathrm{ml}$ of sterile saline.

\section{Plasma Cocaine and Metabolite Analyses}

Venous blood samples (approximately $1 \mathrm{ml}$ ) for cocaine were drawn from a butterfly cannula inserted into the saphenous leg vein and placed into tubes containing potassium oxalate and sodium fluoride. Samples were immediately mixed and were centrifuged within $30 \mathrm{~min}$ of collection, yielding approximately $0.5 \mathrm{ml}$ of plasma, and stored frozen until the time of analysis. Cocaine, BZE, and EME plasma levels were determined by the Nathan Kline Institute for Psychiatric Research (Orangeburg, NY). Cocaine, BZE, and EME were analyzed by capillary gas chromatograph-mass spectrometry using deuterated internal standards, positive chemical ionization, and simultaneous ion monitoring. The assay sensitivity is $1 \mathrm{ng} / \mathrm{ml}$ and intra- and interassay coefficients of variation are less than $6 \%$ for all compounds.

\section{Plasma Hormone Analyses}

Each experimental session, venous blood samples $(2 \mathrm{ml}$ at baseline, $1 \mathrm{ml}$ at other time points) for estradiol and progesterone (only drawn at baseline before the cocaine injection) and LH were drawn from a butterfly cannula and placed into tubes containing SST ${ }^{\circledR}$ gel and clot activator. Samples were centrifuged within $30 \mathrm{~min}$ of collection, yielding approximately $0.5 \mathrm{ml}$ of plasma, and stored frozen until the time of analysis. Estradiol, progesterone, and $\mathrm{LH}$ plasma levels were determined by Dr Michel Ferin at the College of Physicians and Surgeons of Columbia University, Department of Obstetrics and Gynecology (New York, NY). Estradiol and progesterone were measured by a commercial 
solid-phase, chemiluminescent immunoassay (Immulite, Diagnostic Products Co, DPC, Los Angeles, CA) validated for monkeys. Using this assay, progesterone levels $\geqslant 1.5 \mathrm{ng} /$ $\mathrm{ml}$ during the periovulatory or luteal phase indicated that the monkey had a normal ovulatory cycle. The sensitivity of estradiol is $20 \mathrm{pg} / \mathrm{ml}$ and the intra- and interassay coefficients of variation are 4.3 and 10.5 , respectively. The sensitivity of progesterone is $0.2 \mathrm{ng} / \mathrm{ml}$ and the intra- and interassay coefficients of variation are 6.6 and 7.9, respectively. LH plasma levels were measured using a 5day in-house radioimmunoassay (Xiao et al, 1994) in duplicate. Recombinant cynomolgus monkey LH was used as a standard and for iodination, and rabbit antiserum directed against recombinant cynomolgus monkey LH was used as the primary antibody. The sensitivity of $\mathrm{LH}$ is $0.06 \mathrm{ng} / \mathrm{ml}$ and the intra- and interassay coefficients of variation are 7.9 and 13.1, respectively. Reagents were provided by the NIH.

\section{Data Analyses}

Pharmacokinetic analyses. The pharmacokinetic measures of cocaine were determined using a noncompartmental pharmacokinetics data analysis program (PK Solutions Version 2.0, Summit Research Services, Montrose, CO). Plasma drug concentrations were fitted to a single-dose, first-order elimination phase model. For cocaine plasma levels, the peak $\left(C_{\max }\right)$, the estimated time to peak $\left(T_{\max }\right)$, and half-time $\left(T_{1 / 2} ;\right.$ based on the volume of distribution normalized by animal weight and systemic clearance) of cocaine were calculated for each monkey and each dose.

Statistical analyses. Baseline levels of estradiol, progesterone, and LH were analyzed separately using a one factor repeated-measures analyses of variance (ANOVA) with Phase (Menses, Follicular, Periovulatory, Luteal) as the factor. To assess the time course of cocaine, BZE, and EME, these measures were analyzed separately using a three factor repeated-measures ANOVA with Phase as the first factor, Dose $(0.25,0.50,1.00 \mathrm{mg} / \mathrm{kg})$ as the second factor, and Time (6 time points per measure) as the third factor. For LH, since there were menstrual cycle differences in baseline levels, LH data were analyzed as percent change from baseline using a three factor repeated-measures ANOVA with Phase as the first factor, Dose (including $0 \mathrm{mg} / \mathrm{kg}$ cocaine) as the second factor, and Time as the third factor. For the other pharmacokinetic measures described above, each one was analyzed separately using a two factor repeated-measures ANOVA with Phase as the first factor and Dose as the second factor.

For all analyses, results were considered statistically significant if $p<0.05$, using Huynh-Feldt corrections where appropriate.

\section{RESULTS}

All five female monkeys had normal ovulatory menstrual cycles ranging in length from 21 to 34 days (mean of 29.2 days). Table 1 shows the mean plasma levels of estradiol, progesterone, and LH (measured at baseline each session) at each phase of the menstrual cycle. Plasma levels of estradiol
Table I Baseline Hormone Plasma Levels as a Function of Menstrual Cycle Phase*

\begin{tabular}{lccc}
\hline Phase & Estradiol (pg/ml) & Progesterone (ng/ml) & LH (ng/ml) \\
\hline Menses & $60.40( \pm 19.63)$ & $0.38( \pm 0.17)$ & $0.89( \pm 0.30)$ \\
Follicular & $109.85( \pm 88.57)^{\mathrm{a}, \mathrm{c}, \mathrm{d}}$ & $0.38( \pm 0.15)$ & $1.11( \pm 0.35)$ \\
Periovulatory & $53.05( \pm 43.31)$ & $2.09( \pm 1.72)^{\mathrm{a}, \mathrm{b}}$ & $1.16( \pm 0.44)^{\mathrm{a}}$ \\
Luteal & $60.15( \pm 19.40)$ & $2.78( \pm 2.21)^{\mathrm{a}, \mathrm{b}}$ & $1.00( \pm 0.33)$ \\
\hline
\end{tabular}

*Values represent the mean and \pm I SD.

For each hormone, comparisons were conducted across the four phases. andicates significant difference from menses.

bindicates a significant difference from follicular.

Indicates a significant difference from periovulatory.

${ }^{\mathrm{d}} \mathrm{A}$ significant difference from luteal.

were significantly higher in the follicular phase compared to the other three phases ( $p$ 's $<0.001$ ), whereas plasma levels of progesterone were significantly higher in the periovulatory and luteal phases compared to the menstrual and follicular phases $(p$ 's $<0.01)$. In addition, baseline plasma levels of $\mathrm{LH}$ were highest during the periovulatory phase and this was significantly different compared to the menstrual phase $(p<0.03)$.

Although no structured behavioral ratings were conducted each session, cocaine produced mydriasis, increased agitation, restlessness, and motor activity and decreased appetite as evidenced by the refusal of food treats (eg raisins, M\&Ms). These effects were not observed when saline was injected. After active doses of cocaine, particularly 0.50 and $1.00 \mathrm{mg} / \mathrm{kg}$, the onset of behavioral effects was observed within $5 \mathrm{~min}$ and lasted up to $30 \mathrm{~min}$ postinjection.

Figure 1 shows cocaine plasma levels as a function of cocaine dose, time within session, and menstrual cycle phase. Cocaine plasma levels increased as a function of Dose $(\mathrm{F}(2,8)=100.48, p<0.0005)$, decreased as a function of Time postinjection $(\mathrm{F}(5,20)=77.28, p<0.0001)$, and there was a Dose $\times$ Time interaction $(\mathrm{F}(10,40)=47.27$, $p<0.0001)$. However, there were no differences in cocaine plasma levels as a function of menstrual cycle phase. Since plasma cocaine levels were not measured earlier than 5 min after the injection, by default, all peak cocaine levels were observed at $5 \mathrm{~min}$. However, as shown in Table 2, based on the estimated $T_{\text {max }}$, cocaine plasma levels peaked between 2.5 and $4.0 \mathrm{~min}$ after the injection, with no significant differences based on cocaine dose or menstrual cycle phase. Table 2 also shows that peak cocaine plasma levels $\left(C_{\max }\right)$ significantly increased as a function of cocaine dose $(\mathrm{F}(2,8)=115.16, p<0.0001)$, with peak levels of approximately 50, 110 , and $290 \mathrm{ng} / \mathrm{ml}$ following $0.25,0.50$, and $1.00 \mathrm{mg} / \mathrm{kg}$ cocaine, respectively. However, there were no differences in peak cocaine plasma levels based on menstrual cycle phase. The half-life of cocaine $\left(T_{1 / 2}\right)$ ranged between 38-49 min, with no differences based on cocaine dose or menstrual cycle phase.

Figure 2 shows BZE plasma levels as a function of cocaine dose, time within session, and menstrual cycle phase. BZE plasma levels increased as a function of Dose $(\mathrm{F}(2,8)=114.17, p<0.0001)$, increased as a function of Time postinjection $(\mathrm{F}(5,20)=15.69, p<0.01)$ and there was 


\section{Cocaine Plasma Levels}


Figure I Cocaine plasma levels following acute intravenous doses of cocaine as a function of time and menstrual cycle phase. Each panel represents increasing cocaine doses and are therefore plotted on different scales to increase the ability to see differences based on menstrual cycle phase. Each data point represents the mean $( \pm$ I SEM) of five rhesus monkeys. Some error bars have been omitted for clarity and the absence of any bars indicates I SEM fell within the area of the data symbol. Time point 0 designates the time the cocaine injection occurred and the first blood sample was collected $5 \mathrm{~min}$ after the injection. a Dose $\times$ Time interaction $(\mathrm{F}(10,40)=7.34, p<0.01)$. Further, there was a Phase $\times$ Time interaction $(\mathrm{F}(15,60)=$ 3.48, $p<0.001)$. BZE plasma levels showed the greatest increases during the luteal phase, particularly following $1.00 \mathrm{mg} / \mathrm{kg}$ cocaine and the smallest increases during the periovulatory phase, particularly following $0.25 \mathrm{mg} / \mathrm{kg}$ cocaine.

Figure 3 shows EME plasma levels as a function of cocaine dose, time within session, and menstrual cycle phase. EME plasma levels increased as a function of Dose $(\mathrm{F}(2,8)=150.37, p<0.0001)$ and there was a Dose $\times$ Time interaction $(\mathrm{F}(10,40)=7.30, p<0.0001)$. Further, there was a Phase $\times$ Time interaction $(\mathrm{F}(15,60)=2.48, p<0.02)$, such that EME plasma levels showed the greatest increases during the luteal phase, particularly following $1.00 \mathrm{mg} / \mathrm{kg}$ cocaine.

Figure 4 shows LH plasma levels, calculated as a percent change from baseline, as a function of cocaine dose and menstrual cycle phase. For clarity, these data were collapsed across all time points postinjection since there was no main effect of time. Overall, there was a main effect of Phase $(\mathrm{F}(3,12)=3.67, p<0.05)$. As shown in Figure 4, the greatest decreases in LH plasma levels relative to baseline occurred during the periovulatory phase; placebo and all doses of cocaine decreased LH plasma levels. In contrast, following $0.25 \mathrm{mg} / \mathrm{kg}$ cocaine, LH plasma levels increased slightly relative to baseline. However, following $0.50 \mathrm{mg} / \mathrm{kg}$ cocaine, $\mathrm{LH}$ plasma levels remained stable or decreased relative to baseline. Interestingly, following $1.00 \mathrm{mg} / \mathrm{kg}$ cocaine, $\mathrm{LH}$ plasma levels increased by approximately $10 \%$ relative to baseline during both the menstrual and follicular phases, whereas LH plasma levels decreased by approximately 20 and $10 \%$ during the periovulatory and luteal phases, respectively. Figure 5 presents the time course data for $\mathrm{LH}$ plasma levels. Following placebo $(0.00 \mathrm{mg} / \mathrm{kg}$ cocaine $)$, there were few changes in LH plasma levels as a function time or menstrual cycle phase and overall LH levels decreased relative to baseline. Following $0.25 \mathrm{mg} / \mathrm{kg}$ cocaine, $\mathrm{LH}$ plasma levels did increase above baseline levels at some time points for all phases tested, except for the periovulatory phase, where only a decrease was observed. Interestingly, following $0.50 \mathrm{mg} / \mathrm{kg}$ cocaine, $\mathrm{LH}$ levels remained relatively stable or slightly decreased across all time points and phases. The greatest changes in LH plasma levels were observed following $1.00 \mathrm{mg} / \mathrm{kg}$ cocaine, with steady increases across the session during menses and the follicular phase, but steady decreases across the session during the periovulatory and luteal phases.

\section{DISCUSSION}

To our knowledge, this is the first study to comprehensively assess the pharmacokinetics of a range of cocaine doses across the menstrual cycle in rhesus monkeys. Overall, although there were minimal differences in the pharmacokinetics of cocaine across the menstrual cycle, the levels of the cocaine metabolites BZE and EME did vary across the menstrual cycle, with both being increased in the luteal phase, particularly following the highest dose of cocaine. In addition, unlike most previous studies, cocaine did not produce consistent increases in LH levels. Rather, the 
Table 2 Pharmacokinetics of Cocaine as a Function Cocaine Dose and Menstrual Cycle Phase ${ }^{a}$

\begin{tabular}{|c|c|c|c|c|}
\hline Cocaine dose and PK measures & Menses & Follicular & Periovulatory & Luteal \\
\hline \multicolumn{5}{|l|}{$0.25 \mathrm{mg} / \mathrm{kg}$ cocaine } \\
\hline$T_{\max }(\min )$ & $4.0( \pm 1.0)$ & $3.0( \pm 1.2)$ & $3.0( \pm 1.2)$ & $2.0( \pm 1.2)$ \\
\hline$C_{\max }(n g / m l)$ & $56.3( \pm 8.2)$ & $60.4( \pm 9.8)$ & $39.0( \pm 8.0)$ & $53.2( \pm 10.9)$ \\
\hline$T_{1 / 2}(\min )$ & $42.1( \pm 4.1)$ & $36.1( \pm 2.7)$ & $36.8( \pm 3.3)$ & $39.5( \pm 7.0)$ \\
\hline$C_{\max }(\mathrm{ng} / \mathrm{ml})$ & II $3.2( \pm 20.8)$ & $109.5( \pm 29.2)$ & $119.7( \pm 23.5)$ & $110.3( \pm 12.1)$ \\
\hline$T_{1 / 2}(\min )$ & $38.0( \pm 7.1)$ & $43.3( \pm 3.7)$ & $38.3( \pm 2.3)$ & $47.3( \pm 7.2)$ \\
\hline \multicolumn{5}{|l|}{$1.00 \mathrm{mg} / \mathrm{kg}$ cocaine } \\
\hline
\end{tabular}

${ }^{a}$ Values represent the mean and \pm I SEM.

change in LH levels depended on menstrual cycle phase and cocaine dose. Lastly, cocaine produced dose-related behavioral changes (eg mydriasis, increased agitation, decreased appetite) that are consistent with the structured behavioral ratings conducted by other studies after acute doses of i.v. cocaine in rhesus monkeys (Wilson et al, 1976; Saady et al, 1994, 1995; Mello et al, 2002).

\section{Pharmacokinetics of Cocaine}

Overall, there were no differences in the pharmacokinetics of cocaine across the menstrual cycle in rhesus monkeys. Based on the estimates from the pharmacokinetic analyses, cocaine plasma levels peaked between 2-4 min after the injection. However, the first cocaine sample was actually measured $5 \mathrm{~min}$ after the injection and the second sample was not measured until $10 \mathrm{~min}$ later ( $15 \mathrm{~min}$ post injection). Several previous studies in monkeys have taken more frequent cocaine blood samples within the first $10 \mathrm{~min}$. Following $0.8 \mathrm{mg} / \mathrm{kg}$ i.v. cocaine, Mello et al (2000) reported that the estimated time to peak for cocaine plasma levels was slightly longer than in the present study, 7.6 and $9.5 \mathrm{~min}$ in midfollicular and midluteal monkeys, respectively. However, other studies in monkeys have observed peak cocaine plasma levels around 2-4 min (Mello et al, 2002; Mendelson et al, 1999a; Zhou et al, 2001), and as early as $1 \mathrm{~min}$ after i.v. cocaine (Saady et al, 1995). In humans, the time to achieve peak cocaine plasma levels after i.v. administration (4-8 min) has been remarkably consistent across studies (Cone, 1995; Evans et al, 1996; Foltin and Fischman, 1991, 1992; Javaid et al, 1978; Jeffcoat et al, 1989; Mendelson et al, 1999b; Perez-Reyes et al, 1994), even though the rates of administration ranged from $10 \mathrm{~s}$ to 1 min. Despite the infrequent sampling in the present study, our findings are relatively consistent with previous studies in monkeys and humans showing that cocaine plasma levels peak rapidly following i.v. injections of cocaine.

In the present study, peak cocaine levels increased as a function of cocaine dose, but there were no differences based on menstrual cycle phase. It is difficult to compare absolute peak cocaine plasma levels across studies since the doses in the present study $(0.25,0.50,1.00 \mathrm{mg} / \mathrm{kg})$ do not completely correspond to those of previous studies in monkeys. In a previous study (Saady et al, 1995), cocaine plasma levels were $296 \mathrm{ng} / \mathrm{ml}$ at $1 \mathrm{~min}$ and $225 \mathrm{ng} / \mathrm{ml}$ at $6 \mathrm{~min}$ after $1.00 \mathrm{mg} / \mathrm{kg}$ i.v. cocaine in a group of male and female monkeys; these cocaine plasma levels are similar to the present study (peak of $292 \mathrm{ng} / \mathrm{ml}$ collapsed across the four phases). Interestingly, one study (Mendelson et al, 1999a) reported that cocaine plasma levels were lower in midfollicular phase female monkeys than male monkeys $10 \mathrm{~min}$ after $0.8 \mathrm{mg} / \mathrm{kg}$ i.v. cocaine. However, these findings were not replicated by the same investigators when male and female monkeys were compared (Mello et al, 1993). In humans, peak cocaine plasma levels have not differed substantially between the follicular and luteal phases of the menstrual cycle following either i.v. (Mendelson et al, 1999b) or smoked cocaine (Evans et al, 2002; Sofuoglu et al, 1999). However, in one study (Mendelson et al, 1999b), cocaine plasma levels tended to be lower in the luteal phase compared to the follicular phase in women following the lower dose of cocaine $(0.20 \mathrm{mg} / \mathrm{kg}$ i.v. $)$. A similar effect was observed in the present study in that cocaine plasma levels tended to be lower in the periovulatory phase following the lowest dose of cocaine $(0.25 \mathrm{mg} / \mathrm{kg}$ i.v. $)$. It is unclear why this effect was also not observed during the luteal phase. Regardless, these findings are interesting because both the periovulatory and luteal phases are characterized by elevated progesterone levels and, as mentioned earlier, the behavioral effects of cocaine and amphetamine appear to be decreased during this time (see review by Lynch et al, 2002), particularly after low doses of cocaine (Evans et al, 2002).

In the present study, the half-life of cocaine ranged between 36 and $49 \mathrm{~min}$, with no differences based on cocaine dose or menstrual cycle phase. These results are consistent with a previous study showing that following $0.8 \mathrm{mg} / \mathrm{kg}$ i.v. cocaine, the half-life of cocaine has ranged from 43 to $60 \mathrm{~min}$ (Mendelson et al, 1999a). However, a 
Benzoylecgonine Plasma Levels
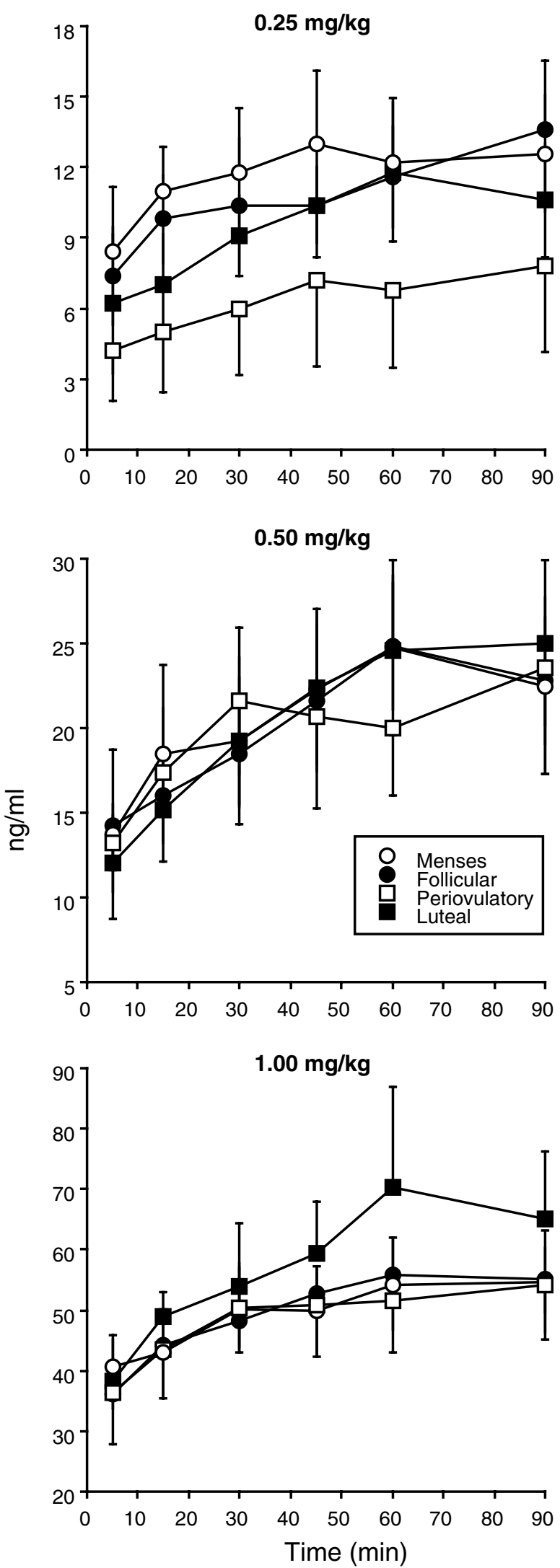

Figure 2 BZE plasma levels following acute intravenous doses of cocaine as a function of time and menstrual cycle phase. See Figure I for details.
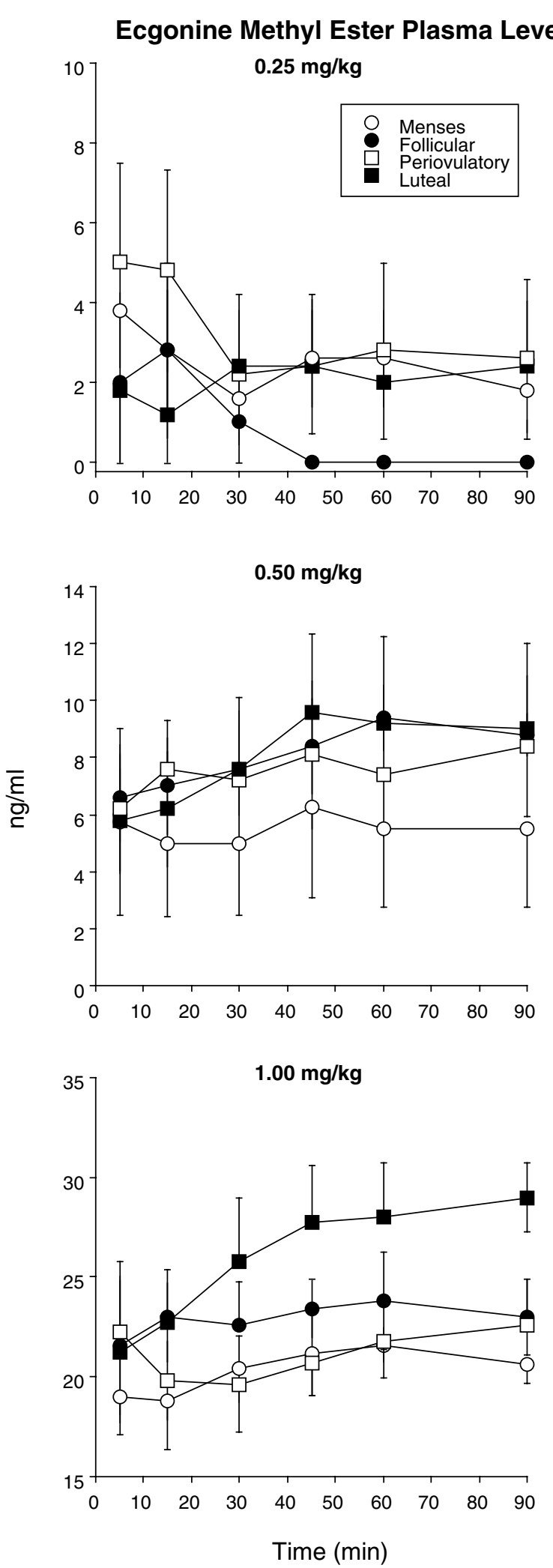

Figure 3 EME plasma levels following acute intravenous doses of cocaine as a function of time and menstrual cycle. See Figure I for details.

shorter half-life (20-24 min) has also been reported following $1.00 \mathrm{mg} / \mathrm{kg}$ i.v. cocaine (Saady et al, 1995). Another study administered $1.00 \mathrm{mg} / \mathrm{kg}$ i.v. cocaine to two pregnant monkeys and the half-life of cocaine was around $57 \mathrm{~min}$ 




Figure 4 LH plasma levels, expressed as percent change from baseline, following acute intravenous doses of cocaine as a function of cocaine dose and menstrual cycle. Each data point represents the mean ( \pm I SEM) of five rhesus monkeys collapsed across time. Some error bars have been omitted for clarity and the absence of any bars indicates I SEM fell within the area of the data symbol.

(Zhou et al, 2001). The half-life of cocaine does appear to be longer after repeated doses of $0.8 \mathrm{mg} / \mathrm{kg}$ compared to $0.4 \mathrm{mg} / \mathrm{kg}$ i.v. cocaine, although no differences were observed between male and female monkeys (Mello et al, 2002).

\section{Pharmacokinetics of the Cocaine Metabolites BZE and EME}

While many studies measure cocaine plasma levels, fewer studies measure or report plasma levels of the major cocaine metabolites (BZE and EME). In the present study, both BZE and EME plasma levels increased as a function of cocaine dose and time during the session. However, since blood samples were only collected up to 90 min after the cocaine injection, it was impossible to determine the time of peak metabolite levels. For instance, in one study conducted in two pregnant monkeys (Zhou et al, 2001), BZE levels peaked approximately $1.7 \mathrm{~h}$ after $1.00 \mathrm{mg} / \mathrm{kg}$ i.v. cocaine, with a half-life of over $5 \mathrm{~h}$. Saady et al (1995) reported comparable BZE plasma levels (but higher EME plasma levels), to the present study $40 \mathrm{~min}$ after $1.00 \mathrm{mg} / \mathrm{kg}$ i.v. cocaine in a group of male and female monkeys.

Although cocaine plasma levels did not vary across the menstrual cycle, both BZE and EME plasma levels showed the greatest increases in the luteal phase compared to the other phases, particularly following the highest dose of cocaine. In rats, BZE plasma levels varied depending on the phase of the estrous cycle in rats (Quiñones-Jenab et al, 1999), with lower BZE plasma levels during estrus and proestrus than during metestrus/diestrus. In the normal female rat, estradiol and progesterone fluctuate over a 4-day estrous cycle, with both hormones peaking during proestrus, whereas during estrus, levels of estradiol are relatively stable and progesterone levels are minimal (Butcher et al, 1974; Smith et al, 1975). In a subsequent study (QuiñonesJenab et al, 2000), ovariectomized female rats treated with estrogen and progesterone had lower BZE plasma levels than females treated with estrogen alone or progesterone alone. Unfortunately, the differences between the monkey menstrual cycle and the rat estrous cycle make comparisons difficult, but taken together the data suggest that the ratio of estradiol and progesterone levels may account for the differences in cocaine metabolite levels. Unfortunately, there are no other published studies that have reported cocaine metabolite levels in normally cycling monkeys; therefore, it is difficult to interpret or speculate on these findings.

To our knowledge, no study in humans has reported on cocaine metabolite levels as a function of menstrual cycle phase. In one study (Evans et al, 2002) that compared the effects of cocaine in women during the follicular and luteal phases, plasma levels of BZE and EME were analyzed, but only the cocaine plasma levels were reported. We went back and analyzed these data (unpublished results). There was a marginal Phase $\times$ Dose interaction $(p<0.059)$, and post hoc analyses indicated that BZE plasma levels were significantly higher in the luteal phase than the follicular phase following repeated doses of $12 \mathrm{mg}$ smoked cocaine. This was not observed following the highest dose of cocaine, but again, without measurements further out into the session, it is unclear if differences would have been detected. Unfortunately, in the elegant cocaine pharmacokinetic study by Mendelson et al (1999b) cocaine metabolite levels were not reported. Other studies in men have shown that BZE levels continue to rise approximately $75 \mathrm{~min}$ after the last cocaine dose (Isenschmid et al, 1992) and can remain elevated and relatively stable $1-6 \mathrm{~h}$ after a single i.v. dose of cocaine (Cone, 1995). Taken together, these findings suggest that in addition to cocaine levels, cocaine metabolite levels may need to be measured to adequately determine whether cocaine administration produces any pharmacokinetic changes across the menstrual cycle.

\section{Effects of Cocaine on LH}

In the present study, cocaine did not produce consistent increases in $\mathrm{LH}$, rather the effects of cocaine on LH plasma levels depended on the dose of cocaine and menstrual cycle phase. Further, following the highest dose of cocaine, LH levels increased during both the menstrual and follicular phases, but decreased during the periovulatory and luteal phases. Moreover, the greatest decreases in LH plasma levels relative to baseline occurred during the periovulatory phase after all cocaine doses, and this decrease was greatest following the highest cocaine dose. Previous studies conducted in laboratory animals and humans have typically shown that LH plasma levels increase following cocaine administration (see Mello and Mendelson, 2002 for a comprehensive review). However, not all studies have consistently reported increases in LH following cocaine and in some cases it has depended on the dose or the menstrual cycle phase. For instance, acute doses of 0.4 and $0.8 \mathrm{mg} / \mathrm{kg}$ i.v. cocaine increased LH levels during the early follicular phase in female monkeys (Mello et al, 1990b), whereas only an acute dose of $0.8 \mathrm{mg} / \mathrm{kg}$ cocaine increased 


\section{LH Plasma Levels}
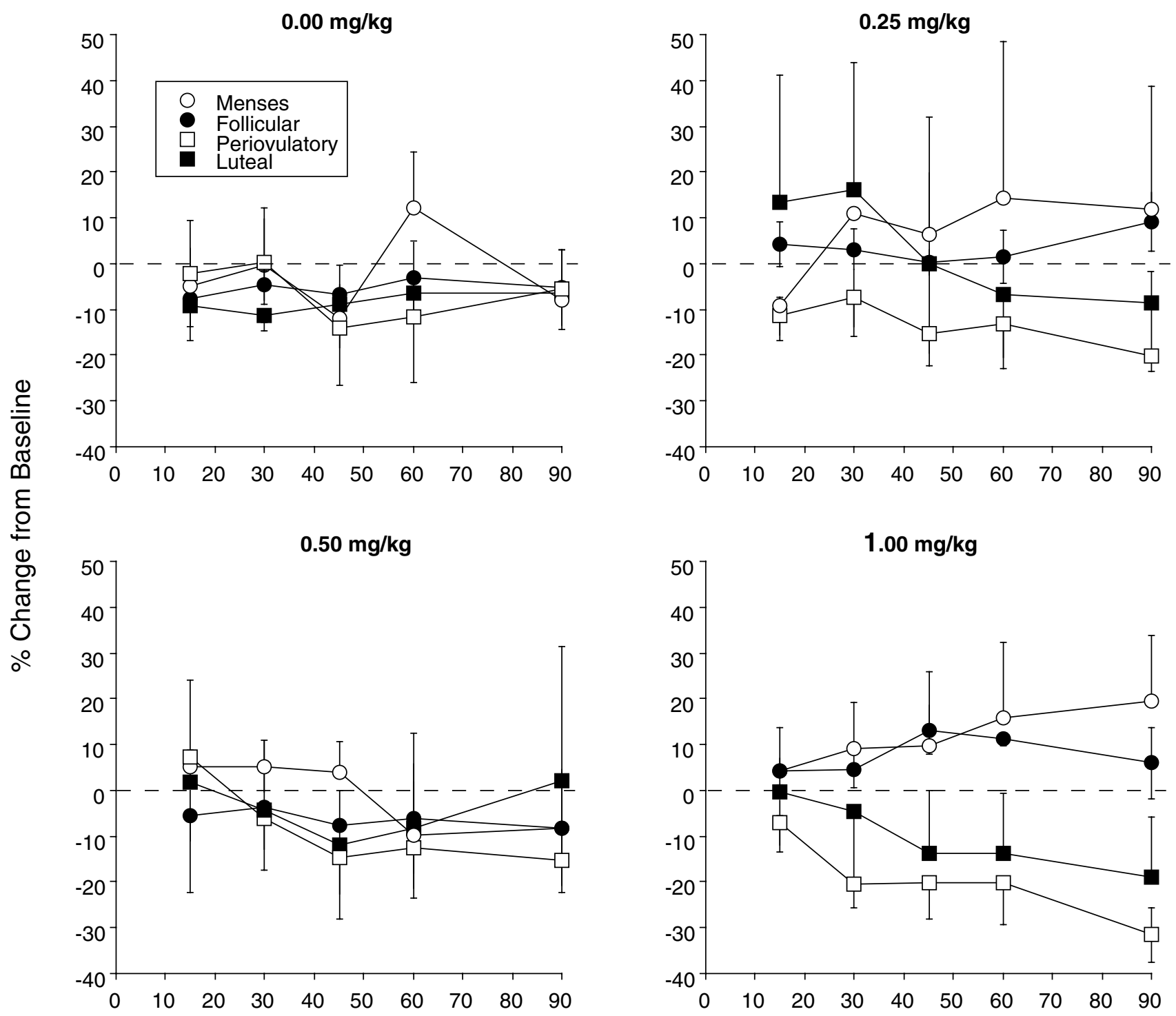

Time (min)

Figure 5 LH plasma levels, expressed as percent change from baseline, following acute intravenous doses of cocaine as a function of cocaine dose, menstrual cycle phase, and time. See Figure 4 for details.

LH levels in the midluteal phase of female monkeys and in male monkeys (Mello et al, 1993). In ovariectomized female monkeys, 0.4 and $0.8 \mathrm{mg} / \mathrm{kg}$ i.v. cocaine failed to alter $\mathrm{LH}$ levels (Mello et al, 1995). In another study using ovariectomized monkeys, large acute doses of cocaine (2$4 \mathrm{mg} / \mathrm{kg}$, i.v.) decreased LH levels, but this was not observed until 2-8 h after cocaine administration (Canez et al, 1992). Dose-related changes in LH have also been observed in rodents following acute doses of cocaine, with low doses increasing LH and high doses decreasing LH (Dada and Horacek, 1991; King et al, 2001; Steger et al, 1981). In humans (Mendelson et al, 2001), $0.4 \mathrm{mg} / \mathrm{kg}$ i.v. cocaine, but not a lower dose $(0.2 \mathrm{mg} / \mathrm{kg})$, increased LH levels in both follicular and luteal phase women. It is unclear whether higher doses of cocaine in humans would decrease $\mathrm{LH}$ levels.

One possible explanation for the lack of consistent increases in LH levels observed in the present study is that blood samples were drawn in monkeys while restrained in a chair. Chair restraint alone has been shown to decrease LH levels, particularly during the follicular phase (Norman et al, 1994). However, those animals were not trained to enter a chair while awake and did not have routine acclimation to chair restraint, as in the present study. Rather, transfer to the chair was accomplished by brief anesthesia with ketamine and animals were restrained for a period of $6 \mathrm{~h}$. 
But other studies have used a chair-restraint system that also anesthetized monkeys, and they have been able to show cocaine-induced increases in LH (Mello et al, 1990b, 1993). Stress has been shown to result in inadequate luteal function (Xiao et al, 2002) and the repeated chair restraint in the present study may have resulted in overall lower levels of LH and progesterone levels, even though the monkeys remained ovulatory. This still does not explain the discrepancies between the present study and those by Mello et al (1990b, 1993). They showed increases in LH during the follicular phase following relatively moderate doses $(0.4 \mathrm{mg} /$ $\mathrm{kg}$ ) of cocaine, similar to the $0.5 \mathrm{mg} / \mathrm{kg}$ dose tested in the present study in which we did not show increases in LH. They also showed increases following $0.8 \mathrm{mg} / \mathrm{kg}$ cocaine, whereas the present study showed increases or decreases following $1.00 \mathrm{mg} / \mathrm{kg}$ cocaine (depending on the menstrual cycle phase). LH is released in a pulsatile manner (Hotchkiss and Knobil, 1994), but in the present study bolus samples were collected, whereas Mello et al (1990b, 1993) used an integrated plasma collection procedure to better capture the pulsatile release. Other factors contributing to the reduced ability of cocaine to increase $\mathrm{LH}$, particularly during the luteal phase, is that LH pulse frequency is dramatically reduced during the luteal phase (Soules et al, 1984) and there is some evidence that progesterone may be responsible for this reduction in $\mathrm{LH}$ pulse frequency (Goodman et al, 1981; Soules et al, 1984). Lastly, during the luteal phase, endogenous opioids also play a role in inhibiting LH secretion (Ferin, 1987; Van Vugt et al, 1984; Yen et al, 1985). Taken together, these studies suggest that the acute effects of cocaine on the stimulation of LH appear to be dependent on both cocaine dose and the phase of the menstrual cycle.

\section{Limitations}

One limitation of this study was the small number of animals tested. Another limitation was that other ovarian and pituitary hormones were not measured after cocaine administration (eg estradiol, progesterone, cortisol, prolactin) and samples were not collected more frequently, or beyond $90 \mathrm{~min}$. Unfortunately, given that monkeys were tested 2-3 times each month, we were restricted by the amount of blood that could be safely drawn at that frequency. The inability to take blood samples more often and for a longer period of time limits the conclusions that can be made, particularly regarding the cocaine metabolite levels and LH levels. In addition, given that monkeys were chair restrained during sessions, it would have been informative to measure cortisol levels since stress can attenuate LH levels (Norman et al, 1994; Xiao et al, 2002). Lastly, the present study only administered cocaine acutely, unlike some recent studies in rodents (Quiñones-Jenab et al, 1999, 2000), monkeys (Mello et al, 2002) and humans (Evans et al, 2002), in which repeated doses of cocaine were tested.

\section{Implications}

The results of the present study, which tested a range of cocaine doses at four distinct phases of the menstrual cycle in monkeys, suggest that there are minimal cocaine pharmacokinetic differences across the menstrual cycle. Cocaine metabolite levels did vary across the menstrual cycle. While these findings are intriguing, they need to be interpreted cautiously due to the variability, small sample size, and absence of comparison data in the literature. Given that cocaine abusers do not typically administer a single dose of cocaine and since the metabolites of cocaine, particularly BZE, continue to rise for several hours after a single dose, it is premature to conclude that there are no pharmacokinetic differences across the menstrual cycle. In the present study some of the more interesting effects occurred during the periovulatory phase, a phase that is routinely ignored in the literature. This is understandable since this phase is difficult to determine given its short duration. However, this is the phase where the most dramatic hormonal fluctuations are occurring. In fact, it is during this phase that the greatest changes in food intake (ie a decrease) are observed in female monkeys (Rosenblatt et al, 1980). Clearly, there are sex differences in response to the behavioral effects of cocaine and a growing body of evidence suggests that fluctuations in gonadal hormones accounts for some of these differences. Therefore, confirmation of the present findings is warranted, preferably using repeated doses of cocaine. The minimally invasive techniques employed in this study, taken together with the fact that the female monkey menstrual cycle is so similar to that of the female human, provide an ideal model for assessing the pharmacokinetic and pharmacodynamic response to cocaine.

\section{ACKNOWLEDGEMENTS}

This research was supported by DA-12675 from The National Institute on Drug Abuse, and approved by the New York State Psychiatric Institute Animal Care and Use Committee. The assistance of April Modrzakowski, Julian Perez, Angel Ramirez, and Drs Mohamed Osman and Sandra Comer is gratefully acknowledged.

\section{REFERENCES}

Butcher RL, Collins WE, Fugo NW (1974). Plasma concentrations of $\mathrm{LH}, \mathrm{FSH}$, prolactin, progesterone and estradiol-17 $\beta$ throughout the 4-day estrous cycle of the rat. Endocrinology 94: 17041708.

Canez MS, Samuels MH, Luther MF, King TS, Schenken RS (1992). Cocaine impairs gonadotropin secretion in oophorectomized monkeys. Am J Obstet Gynecol 167: 1785-1793.

Cone EJ (1995). Pharmacokinetics and pharmacodynamics of cocaine. J Anal Chem 19: 459-478.

Dada MO, Horacek MJ (1991). Acute effects of intravenous administration of cocaine on circulating luteinizing hormone, follicle-stimulating hormone and prolactin concentrations in rats. Res Commun Substance Abuse 12: 197-208.

Evans SM, Cone EJ, Henningfield JE (1996). Arterial and venous cocaine plasma concentrations in humans: relationship to route of administration, cardiovascular, effects and subjective effects. J Pharmacol Exp Ther 279: 1345-1356.

Evans SM, Haney M, Fischman MW, Foltin RW (1999). Limited sex differences in response to binge smoked cocaine use in humans. Neuropsychopharmacology 21: 445-454. 
Evans SM, Haney M, Foltin RW (2002). The effects of smoked cocaine during the follicular and luteal phases of the menstrual cycle in women. Psychopharmacology 159: 397-406.

Ferin M (1987). A role for the endogenous opioid peptides in the regulation of gonadotropin secretion in the primate. Horm Res 28: 119-125.

Foltin RW, Fischman MW (1991). Smoked and intravenous cocaine in humans: acute tolerance, cardiovascular and subjective effects. J Pharmacol Exp Ther 257: 247-261.

Foltin RW, Fischman MW (1992). Self-administration of cocaine by humans: choice between smoked and intravenous cocaine. J Pharmacol Exp Ther 261: 841-849.

Goodman RL, Bittman EL, Foster DL, Karsch FJ (1981). The endocrine basis of the synergistic suppression of luteinizing hormone by estradiol and progesterone. Endocrinology 109: 1414-1417.

Grimm J, See RE (1997). Cocaine self-administration in ovariectomized rats is predicted by response to novelty, attenuated by 17-B estradiol, and associated with abnormal vaginal cytology. Physiol Behav 61: 755-761.

Haney M, Foltin RW, Fischman MW (1998). Effects of pergolide on intravenous cocaine self-administration in men and women. Psychopharmacology 137: 15-24.

Hecht GS, Spear NE, Spear LP (1999). Changes in progressive ratio responding for intravenous cocaine throughout the reproductive process in female rats. Dev Psychobiol 35: 136-145.

Hotchkiss J, Knobil E (1994). The menstrual cycle and its neuroendocrine control. In: Knobil E, Neill JD (eds). The Physiology of Reproduction. Raven Press: New York, NY. pp 711-749.

Isenschmid DS, Fischman MW, Foltin RW, Caplan YH (1992). Concentration of cocaine and metabolites in plasma of humans following intravenous administration and smoking of cocaine. $J$ Anal Toxicol 16: 311-314.

Javaid JL, Fischman M, Schuster CR, Dekirmenjian H, Davis JM (1978). Cocaine plasma concentration: relation to physiological and subjective effects in humans. Science 202: 227-228.

Jeffcoat AR, Perez-Reyes M, Hill JM, Sadler BM, Cook CE (1989). Cocaine disposition in humans after intravenous injection, nasal insufflation (snorting), or smoking. Drug Metab Dispos 17: 153159.

Justice AJH, de Wit H (1999). Acute of $d$-amphetamine during the follicular and luteal phases of the menstrual cycle in women. Psychopharmacology 145: 67-75.

King TS, McNichol M, Canez MS, Javors MA, Schenken RS (2001). Effect of acute administration of cocaine on pituitary gonadotropin secretion in female rats. Reproduction 122: 723-729.

Kosten TR, Kosten TA, McDougle CJ, Hameedi FA, McCance EF, Rosen MI et al (1996). Gender differences in response to intranasal cocaine administration to humans. Biol Psychiatry 39: 147-148.

Lukas SE, Sholar M, Lundahl LH, Lamas X, Kouri E, Wines JD et al (1996). Sex differences in plasma cocaine levels and subjective effects after acute cocaine administration in human volunteers. Psychopharmacology 125: 346-354.

Lynch WJ, Arizzi MN, Carroll ME (2000). Effects of sex and the estrous cycle on regulation of intravenously self-administered cocaine in rats. Psychopharmacology 152: 132-139.

Lynch WJ, Roth MN, Carroll ME (2002). Biological basis of sex differences in drug abuse: preclinical and clinical studies. Psychopharmacology 164: 121-137.

Mello NK, Bowen CA, Mendelson JH (2002). Comparison of plasma cocaine levels during a 'binge' pattern of cocaine administration in male and female rhesus monkeys. Psychopharmacology 164: 19-26.

Mello NK, Mendelson JH (2002). Cocaine, hormones, and behavior: clinical and preclinical studies. Hormones, Brain Behav 5: 665-745.
Mello NK, Mendelson JH, Drieze J, Kelly M (1990a). Acute effects of cocaine on prolactin and gonadotropins in female rhesus monkey during the follicular phase of the menstrual cycle. J Pharmacol Exp Ther 254: 815-823.

Mello NK, Mendelson JH, Drieze J, Kelly M (1990b). Cocaine effects on luteinizing hormone-releasing hormone-stimulated anterior pituitary hormones in female rhesus monkey. J Clin Endocrinol Metab 71: 1434-1441.

Mello NK, Mendelson JH, Kelly M, Bowen C (2000). The effects of cocaine on basal and human chorionic gonadotropin-stimulated ovarian steroid hormones in female rhesus monkeys. J Pharmacol Exp Ther 294: 1137-1145.

Mello NK, Sarnyai Z, Mendelson JH, Diaz-Migoyo N, Kelly M (1995). The acute effects of cocaine on anterior pituitary hormones in ovariectomized rhesus monkeys. J Pharmacol Exp Ther 272: 1059-1066.

Mello NK, Sarnyai Z, Mendelson JH, Drieze JM, Kelly M (1993). Acute effects of cocaine on anterior pituitary hormones in male and female rhesus monkeys. J Pharmacol Exp Ther 266: 804-811.

Mendelson JH, Mello NK, Negus SS (1999a). Effects of luteinizing hormone-releasing hormone on plasma cocaine levels in rhesus monkeys. J Pharmacol Exp Ther 289: 791-799.

Mendelson JH, Mello NK, Sholar MB, Siegel AJ, Kaufman MJ, Levin JM et al (1999b). Cocaine pharmacokinetics in men and in women during the follicular and luteal phases of the menstrual cycle. Neuropsychopharmacol 21: 294-303.

Mendelson JH, Sholar MB, Siegel AJ, Mello NK (2001). Cocaine's effects on luteinizing hormone in women during the follicular and luteal phases of the menstrual cycle and in men.J Pharmacol Exp Ther 296: 972-979.

Misra AL, Giri VV, Patel MN, Alluri VR, Mule SJ (1977). Disposition and metabolism of $[-3 \mathrm{H}]$ cocaine in acutely and chronically treated monkeys. Drug Alcohol Depend 2: 261-272.

Norman RL, McGlone J, Smith CJ (1994). Restraint inhibits luteinizing hormone secretion in the follicular phase of the menstrual cycle in rhesus macaques. Biol Reprod 50: 16-26.

Perez-Reyes M, Jeffcoat AT, Myers M, Sihler K, Cook CE (1994). Comparison in humans of the potency and pharmacokinetics of intravenously injected cocaethylene and cocaine. Psychopharmacology 116: 428-432.

Quiñones-Jenab V, Ho A, Schlussman SD, Franck J, Kreek MJ (1999). Estrous cycle differences in cocaine-induced stereotypic and locomotor behaviors in Fischer rats. Behav Brain Res 101: $15-20$.

Quiñones-Jenab V, Perrotti LI, Mc Monagle J, Ho A, Kreek MJ (2000). Ovarian hormone replacement affects cocaine-induced behaviors in ovariectomized female rats. Pharmacol Biochem Behav 67: 417-422.

Roberts DCS, Bennett SAL, Vickers GJ (1989). The estrous cycle affects cocaine self-administration on a progressive ratio schedule in rats. Psychopharmacology 98: 408-411.

Roberts DCS, Dalton JCH, Vickers GJ (1987). Increased selfadministration of cocaine following haloperidol: effect of ovariectomy, estrogen replacement, and estrous cycle. Pharmacol Biochem Behav 26: 37-43.

Rosenblatt H, Dyrenfurth I, Ferin M, Vande Wiele RL (1980). Food intake and the menstrual cycle in rhesus monkeys. Physio Behav 24: 447-449.

Saady JJ, Bowman ER, Aceto MD (1994). Cocaine-induced rausch: overt behaviour and plasma concentrations in rhesus monkeys. Eur J Drug Metab Pharmacokinet 19: 41-46.

Saady JJ, Bowman ER, Aceto MD (1995). Cocaine, ecgonine methyl ester, and benzoylecgonine plasma profiles in rhesus monkeys. I Anal Toxicol 19: 571-575.

Sell SL, Scalzitti JM, Thomas ML, Cunningham KA (2000). Influence of ovarian hormones and estrous cycle on the behavioral responses to cocaine in female rats. J Pharmacol Exp Ther 293: 879-886. 
Sofuoglu M, Dudish-Poulsen S, Nelson D, Pentel PR, Hatsukami DK (1999). Sex and menstrual cycle differences in the subjective effects from smoked cocaine in humans. Exp Clin Psychopharmacol 7: 274-283.

Soules MR, Steiner RA, Clifton DK, Cohen NL, Aksel S, Bremmer WJ (1984). Progesterone modulation of pulsatile luteinizing hormone secretion in normal women. J Clin Endocrinol Metab 58: 378-383.

Smith MS, Freeman ME, Neill JD (1975). The control of progesterone secretion during the estrous cycle and early pseudopregnancy in the rat: prolactin, gondadotropin and steroid levels associated with rescue of the corpus luteum of pseudopregnancy. Neuroendocrinology 96: 219-226.

Steger RW, Silverman AY, Johns A, Asch RH (1981). Interactions of cocaine and delta-9-tetrahydrocannabinol with the hypothalamic-hypophysial axis of the female rat. Fertil Steril 35: 567-572.

Van Vugt DA, Lam NY, Ferin M (1984). Reduced frequency of pulsatile luteinizing hormone secretion in the luteal phase of the rhesus monkey. Involvement of endogenous opiates. Endocrinology 115: 1095-1101.
Wilson MC, Bedford JA, Buelke J, Kibbe AH (1976). Acute pharmacological activity of intravenous cocaine in the rhesus monkey. Psychopharm Commun 2: 251-261.

Xiao E, Xia L, Shanen D, Khabele D, Ferin M (1994). Stimulatory effects of interleukin-induced activation of the hypothalamopituitary-adrenal axis on gonadotropin secretion in ovariectomized monkeys replaced with estradiol. Endocrinology 135: 2093-2098.

Xiao E, Xia-Zhang L, Ferin M (2002). Inadequate luteal function is the initial clinical cyclic defect in a 12-day stress model that includes a psychogenic component in the rhesus monkey. J Clin Edocrin Metab 87: 2232-2237.

Yen SSC, Quigley ME, Reid RL, Ropert JF, Cetel NS (1985). Neuroendocrinology of opioid peptides and their role in the control of gonadotropin and prolactin secretion. Am J Obstet Gynecol 152: 485-493.

Zhou M, Song Z-M, Lidow MS (2001). Pharmacokinetics of cocaine in maternal and fetal rhesus monkeys at mid-gestation. $J$ Pharmacol Exp Ther 297: 556-562. 